A TEXT-BOOK OF METALLURGY 


\title{
A TEXT-BOOK OF METALLURGY
}

BY

\begin{abstract}
A. R. BAILEY, M.Sc., Ph.D., D.I.C., A.I.M.
ROYAL SCHOOL OF MINES,

MPERIAL COLLEGE OF SCIENGE AND TECHNOLOGY
\end{abstract}

Second Edition

Macmillan Education

1967 
Copyright (C) A. R. Bailey 1960

First Edition 1954

Revised and Reprinted 1956

Second Edition 1960

Reprinted 1961, 1964

Reprinted in this edition 1967

ISBN 978-0-333-01218-5 ISBN 978-1-349-0oo88-3 (eBook)

DOI 10.1007/978-1-349-00088-3

MACMILLAN AND COMPANY LIMITED

4 Little Essex Street London WC 2

also Bombay Calcutta Madras Melbourne

THE MACMILLAN COMPANY OF CANADA LIMITED

70 Bond Street Toronto 2

ST MARTIN'S PRESS INC

175 Fifth Avenue New York NY 10010 


\section{PREFACE}

Tre aim of this book is to provide a modern and thorough introduction to physical and process metallurgy for students of metallurgy at Universities and Technical Colleges. It is hoped that it will meet the very real need that exists for a student's book on general metal. lurgy. Moreover, although presenting an overall picture, the book takes a number of subjects to quite advanced levels. At the end of each chapter a fairly comprehensive list of additional reading is given, so that the book can provide the basis for most of the student's reading.

The first six chapters deal with the nature, structure and properties of metals and alloys, and the methods used for the examination of metallic structures. The treatment includes an introduction to modern atomic theories, the solidification of metals, and a comprehensive account of phase equilibria in binary alloys, together with fairly detailed treatment of the deformation processes in metals and their behaviour under stress in service. The chapter on the physical examination of metallic structures is of necessity a summary of methods and includes most recent developments.

This is followed by consideration of the theoretical and practical aspects of metal production, namely, of ores and their preparation, and of extraction and refining techniques. In each case the reasons for the use of the techniques are discussed and, wherever possible, a physical-chemical background has been developed. The section concludes with a chapter outlining the production of the common base non-ferrous metals, and another dealing with iron and steel manufacture ; brief mention of metallurgical refractories and fuels is also made in these chapters.

The next chapter covers the manufacture of ingots and compares the different procedures for producing castings. The metallurgy of solidification under practical conditions, such as grain arrangement, shrinkage and gas effects, and segregation is also discussed. In the subsequent chapter, the various mechanical working processes are described and compared, as well as electroforming and powder metallurgy. Jointing practice, heat-treatment and the application of protective coatings are also outlined. The treatment of process 
metallurgy in the book is on a general basis, and where appropriate modern developments are described. Lastly, there are chapters on the testing of metals, both by mechanical and non-destructive methods, and on metallurgical pyrometry.

At the end of the book there is a large collection of past examination questions, which have been mainly classified according to the chapter to which they are most relevant. The questions have been selected from degree examination papers of various Universities and from those of the Institution of Metallurgists, City and Guilds of London Institute, and several bodies setting examinations of ordinary National Certificate level. Grateful acknowledgement is made to those bodies which have allowed questions to be reproduced.

With regard to the illustrations, the author wishes to thank Mr. J. Oliver, B.Sc., A.M.I.Mech.E., for making a large number of the drawings. Thanks must go also to the numerous individuals and organisations who have supplied information or allowed their illustrations to be used or copied ; individual acknowledgement is made in each case to the origin of tabulated data and illustrations. Unless otherwise stated, the photographs and drawings of microstructures have been prepared by the author. Finally, in this connection, mention should be made of the great care which has been exercised by Mr. L. E. Carroll, of Messrs. Macmillan, in the preparation of the blocks.

The author acknowledges, as well, the considerable help received from the Joint Library of the Iron and Steel Institute and Institute of Metals, and in particular from Mr. Alan E. Chattin, and the late Mr. R. Elsdon. He has also had much helpful discussion with numerous colleagues.

Finally, the author wishes to pay tribute to the continual and patient guidance which he has received at every stage in the preparation of the book from Mr. A. J. V. Gale; and last but not least, to the forebearance, encouragement and help of his wife.

A. R. BAILEY 


\section{PREFACE TO SECOND EDITION}

DuRnNe the revision of this book in 1956, the opportunity was taken to rewrite certain sections and to modify others. Notably, modifications were made to the section on metallic phases; the accounts of stress-corrosion cracking and damping capacity were rewritten; and the use of terms in tensile testing was adjusted to conform with the 1956 British Standard. A short section was introduced on "FluoSolids" roasting, as well as new information on nickel production.

In the preparation of the present edition, a considerable amount of new material, including new illustrations, has been added, and numerous modifications have been made to the existing text. Thus Chapter 1 has been largely rewritten to incorporate recent ideas on crystallisation, and this has involved corresponding changes in the relevant sections of Chapters 4 and 11. Also, in Chapter 4, some details of eutectic crystallisation have been changed, the sections on ordering and diffusion have been rewritten, and mention has been made of the Kirkendall effect. In Chapter 5, the descriptions of plastic deformation, the dislocation theory, and creep have been considerably expanded and modified ; further details of recrystallisation effects have been given and the derivation of Miller indices has been explained. In a similar manner, the section on powder metallurgy in Chapter 12 has been enlarged and modernised.

The other major additions are accounts of the following subjects : shape of microstructure, zone refining, metallography of radioactive metals and new techniques in electron microscopy; and on the extraction side, filtering, blast-furnace production of zinc, the metallurgy of titanium and uranium (including ion-exchange and solventextraction processes), and the screening and sintering of iron ores.

Minor changes or additions, worthy of mention, refer to defects in crystals, brittle fracture, cathodic-vacuum etching, electrolytic polishing, phase-difference and polarised-light techniques, field ion microscope, electron probe micro-analyser, X-ray microscopy methods, "FluoSolids" reactor, electrolysis of nickel sulphide, control of moisture content of blast for iron smelting, special steelmaking processes using oxygen, stoelmaking in the arc-furnace, arc- 
melting, carbon-dioxide, shell moulding and other specialised casting processes, planetary rolling, and new pyrometers.

Finally, the reading lists have been brought up to date, and more equilibrium diagrams have been inserted in Appendix 2. In addition, a fairly lengthy Appendix has been introduced, entitled " Notes on Writing Metallurgical Reports ". It is hoped that this will materially help students in an aspect of their work that is generally found difficult, and that at the present time is receiving strong criticism.

During the preparation of this edition, the author has profited considerably from discussions with numerous colleagues at the Im. perial College of Science and Technology.

A. R. BAILEY 


\section{CONTENTS}

CHAP.

PAGE

1. Crystallography of Pure Metals 1

2. Atomic Structure and Cohesion between Atoms 17

3. Binary amloying 31

4. Constitutional Diagrams of Brnary Alloying 49

5. Effects of Stress on Metals 93

6. Physical Examination of the Internal Structures of Metals 134

7. Metal Winning : Occurrence and Ore-Preparation 176

8. Metal Winning: General Methods of Extraction AND ReFining 212

9. Metal Winning: Production of Non-Ferrous METALS

10. Metal Winning: Iron- and Steel-Making 313

11. Metal Melting, Alloying and Casting in Practice 355

12. Mechanical Working and Other Shaping and Treating Processes

13. Testing Metals 447

14. Temperature Measurements in Metallurgy 472

Appendix 1. Elements and theIr Electron Groups 497

Appendix 2. Equilibrium Diagrams of Important Brnary Alloy Systems $\quad 500$

Appendix 3. Blast-Furnace Production of Zinc 514e

Appendix 4. Notes on Writing Metallurgical 514h REPORTS

QUESTIONS $\quad 515$

INDEX

ix 
Commonly used Greek Letters

\begin{tabular}{|c|c|c|c|}
\hline$a$ & alpha & $\kappa$ & kappa \\
\hline$\beta$ & beta & $\lambda$ & lambda \\
\hline$\gamma$ & gamma & $\mu$ & mu \\
\hline$\Delta$ & delta & $v$ & nu \\
\hline$\delta$ & & $\pi$ & pi \\
\hline$\epsilon$ & epsilon & $\rho$ & rho \\
\hline$\zeta$ & zeta & $\boldsymbol{\sigma}$ & sigma \\
\hline$\eta$ & eta & $\tau$ & $\operatorname{tau}$ \\
\hline$\theta$ & theta & $\phi$ & phi \\
\hline 6 & iota & $\omega$ & omega \\
\hline
\end{tabular}

